\title{
Effect of alfalfa hay on growth performance, carcass characteristics, and meat quality of growing lambs with ad libitum access to total mixed rations
}

\author{
Ibrahim A. Alhidary ${ }^{1}$, Mutassim M. Abdelrahman ${ }^{1}$, Abdullah H. Alyemni², Rifat Ullah Khan ${ }^{1,3}$, \\ Mohamed Y. Al-Saiady², Ramzi A. Amran ${ }^{1}$, Faisal A. Alshamiry ${ }^{1}$
}

\author{
${ }^{1}$ King Saud University, College of Food and Agriculture Sciences, Department of Animal Production, Riyadh, Saudi Arabia. \\ ${ }^{2}$ ARASCO Company, Riyadh, Saudi Arabia. \\ ${ }^{3}$ The University of Agriculture, Faculty of Animal Husbandry \& Veterinary Sciences, Department of Animal Health, Peshawar, Pakistan.
}

\begin{abstract}
Forty male Naemi lambs were used to evaluate the effect of total mixed rations (TMR) alone or in combination with supplementation of alfalfa hay offered at different schedules on growth, carcass characteristics, and meat quality. Lambs at the age of three months, with an average weight of $28.85 \pm 1.09 \mathrm{~kg}$, were randomly selected and distributed into four different feeding systems, 10 lambs each, as follows: TMR diet (control); TMR plus $100 \mathrm{~g}$ alfalfa hay; TMR plus $200 \mathrm{~g}$ alfalfa hay every two days; and TMR plus $300 \mathrm{~g}$ alfalfa hay every three days. The TMR and fresh drinking water were offered ad libitum. Lambs in the treated groups (with alfalfa hay) had significantly higher body weight, body weight change, dry matter intake, and feed conversion ratio compared with the control. Similarly, slaughter weight, carcass weight (hot and cold), and internal organs weight significantly increased in the treated groups, except for dressing weight percentage, which improved only in the treatment with TMR plus $300 \mathrm{~g}$ alfalfa hay. By contrast, mesentery fat, back fat, and body wall fat decreased in treated groups. Meat quality characteristics indicated that cooking loss and $\mathrm{pH}$ values did not differ between the control and treated groups; however, meat colour (lightness, yellowness, and redness) and pH (1 and $24 \mathrm{~h})$ improved in postslaughter treated groups. Furthermore, no difference was found in texture profile analysis (hardness, springiness, cohesiveness, and chewiness), although the shear force decreased significantly in treated groups. Addition of alfalfa hay offered at the present plan may not only improve the growth and carcass characteristics, but also enhance the meat quality of Naemi lambs. From the labour and economic point of view, TMR plus $300 \mathrm{~g}$ alfalfa hay every three days may be adopted while taking into account the management decision.
\end{abstract}

Key Words: body weight, fat depots, feeding management, slaughter characteristics, supplementation

\section{Introduction}

In the past decades, researchers and producers focused on satisfying consumer demand and the perception of the healthiness of red meat, thereby increasing acceptability and profitability. Recently, due to the increasing demand for local lamb meat, the production of lambs in Saudi Arabia has been shifted from a traditional feeding system to a new intensive fattening system in which the animals have ad libitum access to a high-concentrate diet to ensure fast growth (Alhidary et al., 2016). The post-weaning stage is a critical period during which young lambs are exposed to high-energy diets and can lead to serious complications such as rumen acidosis and abnormal structural and functional development of the

Received February 18, 2016 and accepted April 4, 2016.

Corresponding author: ialhidary@ksu.edu.sa

http://dx.doi.org/10.1590/S1806-92902016000600004

Copyright (c) 2016 Sociedade Brasileira de Zootecnia. This is an Open Access article distributed under the terms of the Creative Commons Attribution License (http://creativecommons.org/licenses/by/4.0/), which permits unrestricted use, distribution, and reproduction in any medium, provided the original work is properly cited. rumen wall (Cavini et al., 2015). In addition, raising lambs on high starch increases the incidence of accumulating fat depots inside the body, which reduces their acceptability at consumer level due to increased awareness of diseases associated with consumption of fats (Resconi et al., 2009; Jacques et al., 2011).

The type of diet influences carcass composition and meat quality in food animals (Lee et al., 2008). To achieve the desired target of weight in lambs, different systems are practised, in which the most important are based on pasture, silage, concentrate, and forage (Bodas et al., 2014). Total mixed rations (TMR) consisting of a balanced amount of all feed ingredients have provided a practical solution to achieve the desired goal in fattening animals (Nissanka et al., 2010; Shekarchian, 2012). A diet based only on forage may produce desirable body weight; however, such a dietary plan is linked to higher feed intake and poor feed efficiency (Casasús et al., 2012). A combination of a certain level of TMR and roughages has produced better rumen conditions (Tufarelli et al., 2011; Tufarelli et al., 2012; Alvarez-Rodríguez et al., 2012; Bodas et al., 2014; Alhidary et al., 2016). However, feeding roughages only to growing 
animals does not support the optimal growth of the rumen (Papi et al., 2011; Alvarez-Rodríguez et al., 2012; Steele et al., 2012). Feeding a highly concentrate diet or a diet plan based on only forages are not beneficial for the rumen health. Therefore, it is essential to formalize a dietary plan that can maintain the rumen health with no negative effects on the performance of the animal and acceptability of its meat.

Evaluation of growth and carcass is necessary to assess the relative efficiency of the animals in converting feed to animal tissue (Resconi et al., 2009; Majdoub-Mathlouthi et al., 2013). Such evaluation system is rarely practiced in Saudi Arabia. In the literature, most of the studies compared the meat traits in lambs raised on concentrate versus forage-based diets at different ratios. In the current study, alfalfa hay was supplemented assuming that the additional neutral detergent fibre provided in the form of alfalfa in the diet of growing Naemi lambs with free access to TMR may positively affect their growth performance, carcass characteristics, and meat quality. Therefore, the purpose of this study was to evaluate the effect of graded levels of alfalfa hay (100 g/day, $200 \mathrm{~g} / 2$ days, $300 \mathrm{~g} / 3$ days) with ad libitum TMR, on the growth, carcass characteristics, and meat quality of growing Naemi lambs. Furthermore, the labour of supplementation is a major practical and economical factor to consider when making management decisions. Therefore, the second objective was to choose the best option from the labour and economic point of view.

\section{Material and Methods}

Growing male Naemi lambs $(\mathrm{n}=40), 3$ months old, average weight $28.85 \pm 1.09 \mathrm{~kg}$, were used in this experiment. Healthy lambs were housed in individual pens. The lambs were randomly divided after 15 days of the adaptation period into four dietary feeding systems (10 lambs/treatment). The dietary systems were: control (TMR); TMR + $100 \mathrm{~g}$ alfalfa hay/day; TMR + $200 \mathrm{~g}$ alfalfa hay/2 days; and TMR + $300 \mathrm{~g}$ alfalfa hay/3 days. The TMR consisted of barley, wheat, palm kernel meal, soybean hulls, wheat bran, alfalfa, salt, limestone, and molasses (Table 1). The TMR was offered at $8.00 \mathrm{~h}$ in automatic feeders ad libitum; the offered amount was increased daily by $20 \%$, and refusals were weighed and discarded. The treatment of alfalfa was continued for three months.

Feed samples were collected weekly for nutritional analysis (AOAC, 1990). Feed intake was recorded weekly until the end of the trial. Body weights were recorded at the beginning of the experiment and every two weeks until the end of the experiment.
At the end of the experiment, lambs (six months old) were fasted for $16 \mathrm{~h}$ with free access to water prior to slaughter. Pre-slaughter weights were determined and the animals were slaughtered in the abattoir by the Halal method. After slaughter, the heads were removed at the atlantooccipital joint and the fore and hind feet were removed at the carpal and tarsal joints, respectively. The animals were partially skinned lying on their back on the floor of the abattoir and then suspended by the hind leg (Achilles tendon) for further skinning. Carcass and non-carcass components were separated and weighed immediately. After skinning and evisceration, stomach, intestines, heart, liver, spleen, and kidneys were removed and weighed (as a $\%$ of the slaughter weight) on an electronic balance after removing the fat. Omental and mesentery fats were removed and weighed. Stomach and intestines were freed of digesta, washed, and then weighed. After determining hot carcass weight, each carcass was chilled to $4{ }^{\circ} \mathrm{C}$ within 45 min post-mortem similarly to the commercial practice. The slaughter procedure and measurements for all the groups were similar. After slaughtering, hot and cold carcass weights were taken and recorded to determine dressing percentage.

pH (1 h and after $24 \mathrm{~h}$ ) was measured at the fourth vertebral region with a $\mathrm{pH}$ meter (Model $\mathrm{pH}$ 211, Hanna Instruments, Woonsocket, RI, USA) equipped with a Crison 507 penetrating electrode (Crison Instruments S.A., Barcelona, Spain). Similarly, meat colour (rectus abdominis) was measured after 1 and subsequently $24 \mathrm{~h}$ post-mortem by using a chroma meter (Konica Minolta, CR-400- Japan)

Table 1 - Chemical composition of total mixed rations and alfalfa (\%, dry matter basis) (mean \pm standard deviation)

\begin{tabular}{lcc}
\hline Ingredient (dry matter basis, \%) & Total mixed ration & Alfalfa \\
\hline Barley & 18.00 & - \\
Wheat & 29.92 & - \\
Palm kernel meal & 20.00 & - \\
Soybean hulls & 12.03 & - \\
Wheat bran & 3.00 & - \\
Alfalfa & 6.00 & - \\
Salt & 0.47 & - \\
Limestone & 2.58 & - \\
Molasses & 7.85 & - \\
Commercial premix & \\
& 0.15 & - \\
Composition (\%) & & $18.1 \pm 0.03$ \\
Dry matter & $91.04 \pm 1.1$ & $18.5 \pm 0.8$ \\
Crude protein & $12.4 \pm 0.3$ & $28.2 \pm 1.2$ \\
Crude fibre & $11.98 \pm 0.12$ & $1.9 \pm 0.03$ \\
Ether extract & $2.61 \pm 0.17$ & $43.5 \pm 2.13$ \\
Neutral detergent fibre & $41.95 \pm 2.11$ & $21.6 \pm 0.8$ \\
Acid detergent fibre & $26.10 \pm 3.42$ & $10.95 \pm 0.1$ \\
Ash & $9.09 \pm 0.4$ &
\end{tabular}

${ }^{1}$ Contained per kg: 10,000 IU vitamin A; 1,000 IU vitamin D; 20 IU vitamin E; $300 \mathrm{mg} \mathrm{Mg} ; 24 \mathrm{mg} \mathrm{Cu} ; 0.6 \mathrm{mg} \mathrm{Co} ; 1.2 \mathrm{mg} \mathrm{I} ; 60 \mathrm{mg} \mathrm{Mn} ; 0.3 \mathrm{mg} \mathrm{Se} ; 60 \mathrm{mg} \mathrm{Zn}$. 
and the CIELAB System (1976) for the colour values (L* for lightness, $\mathrm{a}^{*}$ for redness, and $\mathrm{b}^{*}$ for yellowness). Each colour value was recorded at three locations randomly selected, avoiding blood blots, discolorations, and less covered areas. Back and body wall fat was recorded using an AUSMEAT procedure for lambs as described by Pannier et al. (2014). A muscle sample (150 g) from the longissimus dorsi was collected, placed in polyethylene bags, and stored at $-20{ }^{\circ} \mathrm{C}$ for measurement of tenderness using a Warner-Bratzler shearing test instrument as described by Ponnampalam et al. (2014). Cooking loss was determined according to the method described by Lee et al. (2008). The difference in weight of samples before and after cooking was expressed as a percentage cooking loss.

Data were subjected to analysis of variance (ANOVA) using the General Linear Model (GLM) procedure of the Statistical Analysis System (SAS, version 9.1) according to the following model:

$$
y_{i, j}=\mu+\tau_{j}+\varepsilon_{i, j}
$$

in which $i=1, \ldots, I$ is an index over experimental units (animals); $j=1, \ldots, J$ is an index over treated groups (diet treatments); $y_{i, j}$ are observations; $\mu$ is the grand mean of the observations; $\tau_{j}$ is the $\mathrm{j}$-th treatment effect, a deviation from the grand mean; and $\varepsilon_{i, j}$ are normally distributed zero-mean random errors.

\section{Results}

There were no significant differences between all dietary groups in terms of initial live body weight, but significant $(\mathrm{P}<0.05)$ differences were detected in body weight on a monthly basis or final body weight, with higher values in lambs fed alfalfa compared with control (Table 2). Furthermore, significantly $(\mathrm{P}<0.05)$ higher total body gain, total dry matter intake, and total feed conversion ratio (TFCR) were found in lambs fed TMR with different alfalfa hay feeding protocols compared with TMR alone (Table 3).

The different feeding regimens caused significant $(\mathrm{P}<0.05)$ differences in slaughter weight, hot carcass, cold carcass, heart, empty stomach, empty body, liver, spleen, kidneys, empty intestine, and dressing percentages (Table 4). Lambs fed alfalfa with different protocols showed significantly $(\mathrm{P}<0.05)$ higher values for slaughter weight, cold carcass weight, spleen weight, kidney weight, and chill shrink percentage compared with control. No significant difference was found in omental fat between control and treated groups; however, mesentery fat, back fat, and body wall fat decreased significantly $(\mathrm{P}<0.05)$ in treated groups (Table 5).
There was no significant difference in cooking losses and $\mathrm{pH}(1$ and $24 \mathrm{~h})$ between control and treated groups (Table 6). Water-holding capacity decreased significantly $(\mathrm{P}<0.05)$ in treated groups. Lightness $\left(\mathrm{L}^{*}\right)$ and redness $\left(\mathrm{a}^{*}\right)$ were significantly low $(\mathrm{P}<0.05)$ in treated groups, while yellowness $\left(\mathrm{b}^{*}\right)$ was significantly $(\mathrm{P}<0.05)$ high in treated groups when measured 1 and $24 \mathrm{~h}$ after slaughter.

The highest shear value (the least tender meat) was attained by lambs from control group $(4.16 \mathrm{~kg})$. Shear force decreased significantly $(\mathrm{P}<0.05)$ in treated groups (Table 7). The different feeding systems did not cause any significant effect on the measurements of the texture profile analysis.

\section{Discussion}

An adequate amount of roughages is necessary in TMR for proper structural and functional development of the rumen (van Ackeren et al., 2009). In this research work, weaning weight was similar in the four groups; however, the inclusion level of alfalfa hay in addition to TMR increased feed intake and improved weight gain in the lambs. Previously, in line with our research, it was reported that manipulation of TMR with certain types of roughages may improve feed intake and weight gain in fattening animals (Tufarelli et al., 2012; Bodas et al., 2014). Alfalfa provides higher energy content compared with other grasses

Table 2 - Effects of TMR alone or with different supplementary protocols of alfalfa hay on body weight of growing Naemi lambs

\begin{tabular}{lcccc}
\hline & \multicolumn{4}{c}{ Body weight, kg } \\
\cline { 2 - 5 } & Initial & 1st month & 2nd month & Final \\
\hline TMR & 27.78 & $34.03 \mathrm{a}$ & $40.96 \mathrm{a}$ & $46.26 \mathrm{a}$ \\
$\mathrm{TMR}+100 \mathrm{~g}$ alfalfa hay/day & 29.81 & $38.02 \mathrm{~b}$ & $45.00 \mathrm{~b}$ & $51.95 \mathrm{~b}$ \\
$\mathrm{TMR}+200 \mathrm{~g}$ alfalfa hay/2 days & 29.78 & $37.36 \mathrm{~b}$ & $45.79 \mathrm{~b}$ & $52.25 \mathrm{~b}$ \\
$\mathrm{TMR}+300 \mathrm{~g}$ alfalfa hay/3 days & 28.04 & $36.47 \mathrm{~b}$ & $44.44 \mathrm{~b}$ & $51.93 \mathrm{~b}$ \\
Standard error & 0.97 & 0.95 & 1.12 & 1.16 \\
\hline
\end{tabular}

Means within a row followed by different letters differ significantly $(\mathrm{P}<0.05)$. TMR - total mixed ration.

Table 3 - Effects of TMR alone or with different protocols of alfalfa hay supplement on body weight (BW) change, total DMI, and TFCR of growing Naemi lambs

\begin{tabular}{lccc}
\hline & BW change, kg & DMI, kg & TFCR \\
\hline TMR & $18.48 \mathrm{a}$ & $118.41 \mathrm{a}$ & $6.51 \mathrm{a}$ \\
$\mathrm{TMR}+100 \mathrm{~g}$ alfalfa hay/day & $22.14 \mathrm{~b}$ & $152.26 \mathrm{~b}$ & $6.96 \mathrm{~b}$ \\
$\mathrm{TMR}+200 \mathrm{~g}$ alfalfa hay/2 days & $22.47 \mathrm{~b}$ & $152.38 \mathrm{~b}$ & $6.82 \mathrm{~b}$ \\
$\mathrm{TMR}+300 \mathrm{~g}$ alfalfa hay/3 days & $23.89 \mathrm{~b}$ & $152.06 \mathrm{~b}$ & $6.75 \mathrm{~b}$ \\
Standard error & 0.83 & 0.51 & 0.22 \\
\hline
\end{tabular}

Means within a row followed by different letters differ significantly $(\mathrm{P}<0.05)$.

TMR - total mixed ration; DMI - dry matter intake; TFCR - total feed conversion ratio. 
Table 4 - Effects of TMR alone or with different protocols of alfalfa hay supplement on the weight of body components of growing Naemi lambs

\begin{tabular}{|c|c|c|c|c|c|}
\hline & Control & TMR $+100 \mathrm{~g}$ alfalfa hay/day & TMR $+200 \mathrm{~g}$ alfalfa hay $/ 2$ days & $\mathrm{TMR}+300 \mathrm{~g}$ alfalfa hay $/ 3$ days & SE \\
\hline Slaughter weight, kg & $52.9 \mathrm{a}$ & $54.69 \mathrm{~b}$ & $54.68 \mathrm{~b}$ & $54.57 \mathrm{~b}$ & 1.42 \\
\hline Hot carcass weight, kg & $25.6 \mathrm{a}$ & $29.57 b$ & $27.65 b$ & $28.08 \mathrm{~b}$ & 0.84 \\
\hline Cold carcass weight, $\mathrm{kg}$ & $25.5 \mathrm{a}$ & $30.92 b$ & $27.07 \mathrm{~b}$ & $28.45 b$ & 0.83 \\
\hline Liver weight, $\mathrm{kg}$ & $0.70 \mathrm{a}$ & $0.83 b$ & $0.86 \mathrm{~b}$ & $0.95 b$ & 0.02 \\
\hline Spleen weight, kg & $0.06 \mathrm{a}$ & $0.08 \mathrm{~b}$ & $0.08 b$ & $0.09 b$ & 0.03 \\
\hline Kidneys weight, $\mathrm{kg}$ & $0.10 \mathrm{a}$ & $0.13 b$ & $0.13 b$ & $0.14 b$ & 0.03 \\
\hline Hot carcass dressing, $\%$ & $50.70 \mathrm{a}$ & $50.56 \mathrm{a}$ & $50.78 \mathrm{a}$ & $49.74 b$ & 0.01 \\
\hline Cold carcass dressing, $\%$ & $50.53 \mathrm{a}$ & $50.43 \mathrm{a}$ & $50.70 \mathrm{a}$ & $48.86 \mathrm{~b}$ & 0.01 \\
\hline
\end{tabular}

Means within a row followed by different letters differ significantly $(\mathrm{P}<0.05)$.

TMR - total mixed ration; SE - standard error.

Table 5 - Effects of TMR alone or with different protocols of alfalfa hay supplement on carcass fat depots of growing Naemi lambs

\begin{tabular}{|c|c|c|c|c|c|}
\hline Characteristic & Control & $\mathrm{TMR}+100 \mathrm{~g}$ alfalfa hay/day & $\mathrm{TMR}+200 \mathrm{~g}$ alfalfa hay $/ 2$ days & $\mathrm{TMR}+300 \mathrm{~g}$ alfalfa hay $/ 3$ days & SE \\
\hline Omental fat, kg & $0.91 \mathrm{a}$ & $0.95 \mathrm{a}$ & $1.00 \mathrm{a}$ & $0.96 \mathrm{a}$ & 0.21 \\
\hline Mesentery fat, $\mathrm{kg}$ & $0.36 \mathrm{a}$ & $0.21 \mathrm{~b}$ & $0.18 b$ & $0.22 b$ & 0.02 \\
\hline Back fat, mm & $10.06 \mathrm{a}$ & $8.40 \mathrm{~b}$ & $8.90 \mathrm{~b}$ & $8.10 \mathrm{~b}$ & 0.03 \\
\hline
\end{tabular}

Means within a row followed by different letters differ significantly $(\mathrm{P}<0.05)$.

TMR - total mixed ration; SE - standard error.

Table 6 - Effects of TMR alone or with different protocols of alfalfa hay supplement on meat quality of growing Naemi lambs

\begin{tabular}{|c|c|c|c|c|c|}
\hline Characteristic & Control & TMR $+100 \mathrm{~g}$ alfalfa hay/day & $\mathrm{TMR}+200 \mathrm{~g}$ alfalfa hay $/ 2$ days & $\mathrm{TMR}+300 \mathrm{~g}$ alfalfa hay $/ 3$ days & SE \\
\hline Cooking loss, $\%$ & 30.70 & 32.00 & 29.98 & 32.16 & 0.12 \\
\hline pH (1 h PM) & 6.16 & 6.07 & 6.17 & 6.23 & 0.09 \\
\hline \multicolumn{6}{|c|}{ Meat color (1 h PM) } \\
\hline L* & $38.10 \mathrm{a}$ & $27.81 \mathrm{~b}$ & $25.27 \mathrm{~b}$ & $28.38 \mathrm{~b}$ & 2.54 \\
\hline$a^{*}$ & $16.30 \mathrm{a}$ & $20.55 b$ & $19.38 b$ & $18.58 b$ & 0.47 \\
\hline $\mathrm{L}^{*}$ & $39.20 \mathrm{a}$ & $45.35 b$ & $43.22 b$ & $46.48 b$ & 0.78 \\
\hline$a^{*}$ & $17.90 \mathrm{a}$ & $23.85 b$ & $24.55 b$ & $23.99 b$ & 0.97 \\
\hline $\mathrm{b}^{*}$ & $7.07 \mathrm{a}$ & $11.40 \mathrm{~b}$ & $9.20 \mathrm{~b}$ & $10.87 \mathrm{~b}$ & 0.66 \\
\hline
\end{tabular}

Means within a row followed by different letters differ significantly $(\mathrm{P}<0.05)$.

TMR - total mixed ration; SE - standard error; PM - post mortem.

Table 7 - Effects of TMR alone or with different protocols of alfalfa hay supplement on shear force, hardness, springiness, cohesiveness, and chewing quality of meat of growing Naemi lambs

\begin{tabular}{|c|c|c|c|c|c|}
\hline Characteristic & Control & TMR $+100 \mathrm{~g}$ alfalfa hay/day & $\mathrm{TMR}+200 \mathrm{~g}$ alfalfa hay $/ 2$ days & $\mathrm{TMR}+300 \mathrm{~g}$ alfalfa hay $/ 3$ days & SE \\
\hline Shear force, $\mathrm{kg}$ & $2.16 \mathrm{a}$ & $1.65 \mathrm{~b}$ & $1.78 \mathrm{~b}$ & $1.62 \mathrm{~b}$ & 0.16 \\
\hline \multicolumn{6}{|c|}{ Texture profile analysis } \\
\hline Springiness & 0.64 & 0.65 & 0.66 & 0.69 & 0.02 \\
\hline Cohesiveness & 0.52 & 0.50 & 0.51 & 0.49 & 0.01 \\
\hline Chewiness & 0.16 & 0.21 & 0.16 & 0.15 & 0.03 \\
\hline
\end{tabular}

Means within a row followed by different letters differ significantly $(\mathrm{P}<0.05)$

TMR - total mixed ration; SE - standard error. 
or grazing, which can result in a low growth rate (Alhidary et al., 2016). From the results of the present study, it could be inferred that free access of lambs to a certain amount of long alfalfa straw may have a beneficial impact on feed intake compared with TMR group and thus increased weight gain and feed efficiency in the respective groups. These results could have positive implications for better ruminal conditions. In line with the previous reports, consumption of roughages supports rumen motility, increases the size and muscular development, and promotes rumination (van Ackeren et al., 2009; Alvarez-Rodríguez et al., 2012). It is generally accepted that more fibre intake results in physical fill of the rumen and thus regulates intake (Jacques et al., 2011). Papi et al. (2011) documented that dry matter and energy intakes as well as body weight decreased when the level of concentrate was increased in the diet of lambs receiving different ratios of alfalfa hay, and concluded that this may be related to rumen acidosis and stasis. Therefore, it is inferred that feeding alfalfa hay in addition to TMR enhanced the feed intake and consequently weight gain of lambs. In the current study, the worst FCR was recorded in the group of lambs fed TMR alone. According to Karim et al. (2007), a higher fat depot (which was observed in this study) reduces FCR and increases the cost of feed per $\mathrm{kg}$ gain in live weight; thus, it is not cost-effective.

This study indicated that carcass weight and organ weight increased when alfalfa hay was supplemented in the lamb diet. In line with our study, Papi et al. (2011) reported that the increasing concentrate level had no beneficial effect on most of the carcass weight. In our experiment, we found that dressing percentage decreased significantly in the treatment with TMR plus $300 \mathrm{~g}$ alfalfa hay every three days. Dressing percentage is an important trait that is affected by age, breed, and nutrition (Karim et al., 2007). The only plausible reason for the reduction of dressing percentage in control group may be the corresponding increase in the fat depots and relatively higher slaughter weight compared with the other treated groups. The dressing percentage of 6-month-olds varies from 48 to $50 \%$ (Karim et al., 2007) which agrees with our findings. The weights of the digestive tract and gastric components are logically related to the type of diet consumed by the ruminants (Archimede et al., 2008). Thus, the carcass dressing was better in treated groups because of better body development.

The result of weight of the internal organs is heavier in the treated groups compared with the control group. In the present study, empty stomach was significantly higher in treated groups, particularly in the treatment with TMR plus $300 \mathrm{~g}$ alfalfa hay compared with the control group. Similar results were reported by Jacques et al. (2011). Our results do not agree with Joy et al. (2008), who reported heavier reticulum in lambs fed a concentrated diet. The heavier empty stomach weight may also partially be due to the corresponding heavier body weight in the treatment with TMR plus $300 \mathrm{~g}$ alfalfa hay. Similarly, the dressing percentage decreased $(\mathrm{P}>0.05)$ in this treatment compared with concentrate-fed lambs. The reduced dressing percentage may probably be due to the removal of heavier internal contents, which correspondingly reduced dressing percentage.

The results showed that omental fat, mesentery fat, back fat, and body wall fat decreased in lambs fed alfalfa hay. These results are in agreement with other researchers who found that lambs on high forage tended to deposit less subcutaneous and intestinal fats (Karim et al., 2007; Papi et al., 2011). Lambs fed a concentrate diet display significantly greater fatness than lambs raised on foragebased diets (Jacques et al., 2011). The reduced carcass fat may also be attributed to lower energy intake (Karim et al., 2007). In addition, high starch consumption in fullconcentrate diets produces higher amounts of propionate, which ultimately increases insulin secretion and stimulates fat synthesis (Jacques et al., 2011).

Just after weaning, young animals fed hay and concentrate may show a different performance and thereby have their meat composition and quality affected (Lee et al., 2008). Dietary feeding systems did not have any influence on the cooking loss of lamb meat in the present study. Lee et al. (2008) reported that dietary feeding did not influence cooking loss in pork and chevon. Meat juiciness is influenced by its water content, which is a major contributor to the sensation of juiciness during eating (Lee et al., 2008). In the present study, the fat colour of the meat $\left(L^{*}, a^{*}\right.$, and $\left.b^{*}\right)$ did not differ between control and treated groups. A relationship exists between concentrate intake and meat colour (Archimede et al., 2008). Undoubtedly, the lambs were slaughtered under similar conditions; lambs supplemented with alfalfa hay showed better meat colour than those fed TMR only, although the final $\mathrm{pH}$ was similar. Similarly, no difference was noted in these parameters between the treated groups. Partially similar results were reported by Carrasco et al. (2009) and Jacques et al. (2011) in the fat tissue of animals raised on pasture. Fat deposition in the animal body is affected by feeding system (Jacques et al., 2011). The colour variations in meat may be the consequence of the amount of green carotenoids stored in the meat (Carrasco et al., 2009). The results of the present study are important from the point of view of consumers satisfaction, as they are more interested in purchasing lean meat. Similar observations were recorded by Lee et al. (2008), who found 
that the brightness and yellowness of meat were higher when the goats were fed a diet consisting of concentrate and hay compared with the concentrate diet alone.

Hardness and springiness increased slightly in the treatment with TMR plus $300 \mathrm{~g}$ alfalfa hay every three days, although cohesiveness and chewiness decreased correspondingly in the same group. The increased hardness and springiness may be due to the lower fat content in the meat of this group. In the current study, shear force decreased significantly in the treated groups compared with control, although it was within the acceptable limit for lambs of about $3 \mathrm{~kg}$ (Webb et al., 2005). Shear force depends upon several factors, including treatment of the animals prior to slaughter, post-mortem technique, type of muscle, and its preparation (Lee et al., 2008).

\section{Conclusions}

A dietary plan based on ad libitum total mixed ration with addition of alfalfa at the rate of $300 \mathrm{~g}$ every three days not only enhances the growth performance but also improves carcass characteristics and meat quality of Naemi lambs. In addition, this treatment is more economical from the management point of view.

\section{Acknowledgments}

The authors extend their appreciation to the Deanship of Scientific Research at King Saud University for funding this work through research group no. RG- 1436-021. Special thanks to Eng. Rafat Mahmoud and Dr. Abdelrahman Jaralnabi for their help in sample collection, preparation, and analyses.

\section{References}

Alhidary, I.; Abdelrahman, M. M.; Alyemni, A. H.; Khan, R. U.; Al-Mubarak, A. H. and Albaadani, H. H. 2016. Characteristics of rumen in Naemi lamb: Morphological changes in response to altered feeding regimen. Acta Histochemica (in press). http:// dx.doi.org/10.1016/j.acthis.2016.03.002

Alvarez-Rodríguez, J.; Monleón, E.; Sanz, A.; Badiola, J. J. and Joy, M. 2012. Rumen fermentation and histology in light lambs as affected by forage supply and lactation length. Research in Veterinary Science 92:247-253.

AOAC - Association of Official Analytical Chemists. 1990. Official methods for analysis. 15th ed. Association of Official Analytical Chemists, Washington, DC.

Archimede, H.; Pellonde, P.; Despois, P.; Etiienne, T. and Alexandre, G. 2008. Growth performances and carcass traits of Ovin Martinik lambs fed various ratios of tropical forage to concentrate under intensive conditions. Small Ruminant Research 75:162-170.
Bodas, R.; Posado, R.; Bartolome, D. J.; de Paz, M. J.; Herraiz, P.; Rebollo, E.; Gomez, L. J. and Garcia, J. J. 2014. Ruminal pH and temperature, papilla characteristics, and animal performance of fattening calves fed concentrate or maize silage-based diets. Chillan Journal of Agriculture 74:280-285.

Carrasco, S.; Ripoll, G.; Sanz, A.; Álvarez-Rodríguez, J.; Panea, B.; Revilla, R. and Joy, M. 2009. Effect of feeding system on growth and carcass characteristics of Churra tensina light lambs. Livestock Science 121:56-63.

Casasús, I.; Ripoll, G. and Albertí P. 2012. Use of maize silage in beef heifers fattening diets: effects on performance, carcass and meat quality. ITEA-Información Técnica Económica Agraria 108:191-206.

Cavini, S.; Iraira, S.; Siurana, A.; Foskolos, A. Ferret, A. and Calsamiglia, S. 2015. Effect of sodium butyrate administered in the concentrate on rumen development and productive performance of lambs in intensive production system during the suckling and the fattening periods. Small Ruminant Research 123:212-217.

Jacques, J.; Berthiaume, R. and Cinq-Mars, D. 2011. Growth performance and carcass characteristics of Dorset lambs fed different concentrates: Forage ratios or fresh grass. Small Ruminant Research 95:113-11.

Joy, M.; Alvarez-Rodriguez, J.; Revilla, R.; Delfa, R. and Ripoll, G. 2008. Ewe metabolic performance and lamb carcass traits in pasture and concentrate-based production systems in Churra Tensina breed. Small Ruminant Research 75:24-35.

Karim, S. A.; Porwal, K.; Kumar, S. and Singh, V. K. 2007. Carcass traits of Kheri lambs maintained on different system of feeding management. Meat Science 76:395-401.

Lee, J. H.; Kouakou, B. and Kannan, G. 2008. Chemical composition and quality characteristics of chevon from goats fed three different post-weaning diets. Small Ruminant Research 75:177-184.

Majdoub-Mathlouthi, L.; Said, B.; Say, A. and Kraiem, K. 2013. Effect of concentrate level and slaughter body weight on growth performances, carcass traits and meat quality of Barbarine lambs fed oat hay based diet. Meat Science 93:557-563.

Nissanka, N. P. C.; Bandara, R. M. A. and Disnaka, K. G. 2010 Comparative study on feeding of total mixed ration vs conventional feeding on weight gain weaned Friesian heifers under tropical environment. Journal of Agriculture Science 5:42-51.

Pannier, L.; Pethick, D. W.; Geesink, G. H.; Ball, A. J.; Jacob, R. H. and Gardner, G. E. 2014. Intramuscular fat in the longissimus muscle is reduced in lambs from sires selected for leanness. Meat Science 96:1068-1075.

Papi, N.; Mostafa-Tehrani, A.; Amanlou, H. and Memarian, M. 2011. Effects of dietary forage-to-concentrate ratios on performance and carcass characteristics of growing fat-tailed lambs. Animal Feed Science and Technology 163:93-98.

Ponnampalam, E. N.; Butler, K. L.; Jacob, R. H.; Pethick, D. W.; Ball, A. J.; Edwards, J. E. H.; Geesink, G.; Hopkins, D. L. 2014. Health beneficial long chain omega-3 fatty acid levels in Australian lamb managed under extensive finishing systems. Meat Science 96:1104-1110

Resconi, V. C.; Campo, M. M.; Font i Furnols, M.; Montossi, F. and Sanudo, C. 2009. Sensory evaluation of castrated lambs finished on different proportions of pasture and concentrate feeding systems. Meat Science 83:31-37.

Shekarchian, S. 2012. Research about indicate the effect of concentrate feeding strategy on milk production and composition in dairy cows in Esfahan. Iranian Journal of Veterinary Research 5:63-67.

Steele, M. A.; Greenwood, S. L.; Croom, J. and McBride, B. W. 2012. An increase in dietary non-structural carbohydrates alters 
the structure and metabolism of the rumen epithelium in lambs. Canadian Journal of Animal Science 92:123-130.

Tufarelli, V.; Khan, R. U. and Laudadio, V. 2011. Feeding of wheat middlings in lamb total mixed rations: effects on growth performance and carcass traits. Animal Feed Science and Technology 17:130-135.

Tufarelli, V.; Khan, R. U.; Mazzei, D. and Laudadio, V. 2012. Performance and carcass measurements of ewe lambs reared in a feedlot and fed wheat (Triticum durum Desf.) middling total mixed rations in the summer season. Tropical Animal Health and Production 44:779-784.

van Ackeren, C.; Steingab, H.; Hartung, K.; Funk, R. and Drochner, W. 2009. Effect of roughage level in a total mixed ration on feed intake, ruminal fermentation patterns and chewing activity of early-weaned calves with ad libitum access to grass hay. Animal Feed Science and Technology 153:48-59.

Webb, E. C.; Casey, N. H. and Simela, L. 2005. Goat meat quality. Small Ruminant Research 60:153-166. 